\title{
Oberman ou le sublime négatif, textes réunis par $\mathrm{F}$. Bercegol
}

\section{Nicolas Brucker}

\section{(2) OpenEdition}

10 Journals

\section{Édition électronique}

URL : http://journals.openedition.org/studifrancesi/8956

DOI : 10.4000/studifrancesi.8956

ISSN : 2421-5856

Éditeur

Rosenberg \& Sellier

\section{Édition imprimée}

Date de publication : 1 octobre 2008

Pagination : 468-469

ISSN : 0039-2944

\section{Référence électronique}

Nicolas Brucker, «Oberman ou le sublime négatif, textes réunis par F. Bercegol », Studi Francesi [En ligne], 155 (LII | II) | 2008, mis en ligne le 30 novembre 2015, consulté le 12 janvier 2021. URL : http:// journals.openedition.org/studifrancesi/8956; DOI : https://doi.org/10.4000/studifrancesi.8956

Ce document a été généré automatiquement le 12 janvier 2021.

\section{(c) (i) (9)}

Studi Francesi è distribuita con Licenza Creative Commons Attribuzione - Non commerciale - Non opere derivate 4.0 Internazionale. 


\title{
Oberman ou le sublime négatif, textes réunis par F. Bercegol
}

\author{
Nicolas Brucker
}

\section{RÉFÉRENCE}

Oberman ou le sublime négatif, textes réunis par F. BERCEGOL, en hommage à et sous le patronage de B. DIDIER, Paris, Éditions Rue d'Ulm, 2006 («Coup d'essai»), pp. 123.

1 Ce recueil de textes prouve, s'il en était besoin, que les études senancouriennes se portent bien. Dans son article, Fabienne BERCEGOL (pp. 1-23) rappelle à grands traits le destin critique d'Oberman, dont on a fêté en 2004 le bicentenaire, avant d'étudier dans cette œuvre la négation du romanesque. Renonçant aux conventions du genre, Senancour choisit la voie d'une écriture fragmentaire et d'une œuvre ouverte, échappant ainsi au dilemme du roman. De manière paradoxale, le roman, tout en prétendant faire la peinture de l'amour, congédie les stratégies narratives habituelles, marque la rupture avec les codes en éliminant l'événement amoureux et en affaiblissant l'intrigue. Le rapprochement avec Dominique de Fromentin, qui clôt l'article, est très éclairant sur ce point.

2 L'absence de référence à l'actualité politique, examinée par Caroline JACOT GRAPA (pp. 25-46), semble s'expliquer par les mêmes raisons. Si le texte élide systématiquement les références historiques, c'est pour privilégier le domaine de l'affect. Ce non-dit historique, véritable déni en tant que narration, se double d'une contestation du modèle politique et de la promotion d'une autre socialité, celle de l'homme solitaire, à l'écart du monde et de ses aliénations. Par cette revendication d'une autonomie individuelle, par l'affirmation de la vertu comme principe social majeur, Senancour n'annonce-t-il pas une fin du politique?

3 La simplicité, donnée éthique et esthétique étudiée par Marianne BURY (pp.47-58), traduit chez Senancour la nostalgie d'un âge d'or, en même temps qu'elle signifie le refus de toute rhétorique. Entre classicisme et romantisme, Senancour redéfinit les 
catégories héritées de l'âge classique pour se les réapproprier. À côté de valeurs comme l'harmonie, la beauté ou la grandeur, figure la simplicité, qui permet d'atteindre au sublime. Le caractère naturel du style trouve son correspondant dans la mélodie, et obéit au même principe d'économie: comment avec peu de moyens produire un maximum d'effet? Senancour, à contre-courant de l'évolution littéraire, réactive à l'orée du $\mathrm{XIX}^{\mathrm{e}}$ siècle la simplicité héritée des classiques. Nicolas P EROT (pp. 59-74) interroge lui aussi cette transparence du langage et, par une rigoureuse analyse stylistique, met à jour les procédés par lesquels Senancour efface tout effet littéraire pour n'en laisser que la trace. Il en résulte une écriture blanche, qui tend asymptotiquement vers le zéro ou vers ce néant qui fascine tant le solitaire.

Patrick MAROT (pp.75-90) s'intéresse au paysage dans Oberman comme point de rencontre entre le sujet et la nature ou, plus précisément, entre intériorité et extériorité, chacune échangeant ses qualités, chacune répondant à l'autre. Il montre que la hiérarchie traditionnelle entre récit et description se trouve inversée: c'est le descriptif qui engendre le récit, qui unifie la narration événementielle en la soumettant à une temporalité unique. Le paysage est le lieu de la coopération des facultés cognitives, et le passage de la description à la rêverie n'est que la continuation d'une même pratique selon des modalités différentes. Insistant sur sa dimension symbolique, l'auteur termine en évoquant les images synesthésiques qui, révélatrices d'une unité sublime du monde, mènent vers un au-delà de l'aperception et de l'expression, l'espace et l'écriture se rejoignant dans une commune expérience.

Plus strictement thématique, l'étude de Claude REICHLER (pp. 91-107) s'intéresse à l'air et aux phénomènes météorologiques. Fortement présents dans la culture de la fin du XVIII siècle, ceux-ci manifestent le passage d'une relation unifiante de l'homme à l'univers à une relation symbolique. En plus des propriétés chimiques, physiques et optiques, les phénomènes aériens en possèdent de cénesthésiques, qui permettent une interaction entre le physiologique et le psychologique, interface entre le monde et l'homme, mais aussi entre l'homme et l'au-delà. Revisités au seuil du romantisme, ils manifestent une énergie tant individuelle que sociale. Oberman est habité par cette force, son ondoyante sensibilité répondant à l'incessant changement des paysages météorologiques, symbole de la mutabilité universelle. L'ouvrage se termine par une très utile bibliographie et un index nominum.

6 Souvent érudites, toujours suggestives, ces six études ajoutent à notre connaissance du grand roman de Senancour; elles forment surtout un ensemble d'une indéniable cohérence, les analyses se répondant l'une l'autre. Le parti pris des éditeurs de n'aborder la question du sublime négatif que sous l'angle poétique est pour beaucoup dans cette unité. On regrette cependant qu'aucun prolongement philosophique ou théologique ne lui ait été donné. 